\title{
Design of a Multi-Layer Interior Ferrite Permanent Magnet Synchronous Machine for Traction Applications
}

\author{
B. Xia, W. Fei, P. C. K. Luk, D. Wu \\ Electric Power and Drives Group, School of Engineering, Cranfield University, Cranfield MK43 OAL, U.K.
}

Keywords: Ferrite magnet, flux-focusing, interior permanent magnet, multi-layer, traction motor.

\begin{abstract}
A novel design of interior ferrite permanent magnet synchronous machine with multi-layer configuration is proposed for traction applications. Although the ferrite magnet can be disadvantaged by its low residual flux density and energy product, it is proposed that flux-focusing and multi-layer configurations can be utilized to harness both permanent magnet (PM) torque and reluctance torque to recoup the loss of the PM torque due to its intrinsic property. The machines with up to three-layer magnets are presented and evaluated comprehensively. The results suggest that the two-layer machine provides the best performance among the three configurations. Furthermore, compared against a commercial rare-earth equivalent, the proposed ferrite machine is shown to have nearly the same torque with $32 \%$ less electromagnetic losses. The findings underpin interior ferrite permanent magnet synchronous machine as an attractive alternative for traction applications.
\end{abstract}

\section{Introduction}

Electrification of road transport is currently given top priority in the EU, the US and other countries, as the agenda for energy and climate change continues to dominate policy debates worldwide. The electric drive-train is a key subsystem of electric vehicles and is therefore important in the electrification development. The permanent magnet synchronous machine (PMSM), with distinct advantages including high torque density, excellent efficiency, good overload capability and superior controllability, has become one of the most promising candidates for electric propulsion [1-3]. Rare-earth permanent magnet (PM) materials, which have high residual flux density and energy, have been used in virtually all types of high performance PM machines [4-7]. They have been, for example, used in the Toyota Prius, and in giant wind generators due to their high torque and power densities [8]. They are also routinely used in many 'green' energy applications.

However, price hikes and supply chain uncertainty of rareearth materials as a result of high demand and China's political concerns would continue to hinder any large-scale deployment of rare-earth PMSMs. Therefore, it is of strategic importance to develop alternative high performance electric machines with less or even no rare-earth PM materials, if the demand for the full electrification of road transport is to be met. Low-price and non-strategic ferrite PM materials are being considered as a potential solution for high performance electric machines for traction applications [9-11]. However, the ferrite magnet has much lower residual flux density and energy product than that of the rare-earth's. Thus, new geometric configurations need to be developed for ferrite PMSMs to achieve comparable torque density.

There are two types of electromagnetic torques in PMSM: the PM torque arising from the interactions between the PM field and the armature windings, and the reluctance torque produced by the winding inductance variation with the rotor position due to the rotor saliency. As the strength of the ferrite PM materials is much weaker than that of rare-earth, fluxfocusing techniques are used to increase the open-circuit airgap flux density to reasonable level. However, the PM torque thus generated will still be relatively low [12]. Thus, high saliency should also be employed to harness both PM and reluctance torques so that the overall machine performance will be further enhanced [13,14]. The spoke type interior PMSM (IPMSM), namely flux squeeze machine, which concentrates the fluxes from the PM to achieve approximately the same air-gap flux density as the rare-earth machine $[15,16]$, has attracted much attention. Further improvements over the conventional spoke type structure have been reported. Large rotor overhang [17] and wing shaped spoke type PMs [18] are proposed to achieve high power density while an assistant Halback ring-type PM is applied to increase the torque output $[19,20]$. However, these designs are of complex rotor structure and high magnet consumption. Remarkably, there is no attempt to utilise the reluctance torque component in these designs. One notable attempt to use the spoke ferrite PMSM to harness reluctance torque and to improve flux weakening capability is found in [21].

The literature review strongly suggests that given the vast design space of multi-layer ferrite configurations such as the spoke type, the potentials of the new generation of machines deriving from these configurations are still poorly understood. In this paper, multi-layer ferrite magnet configurations are studied, with due consideration given to mechanical integrity, for their suitability to bend PM and reluctance torque components. The rare-earth interior PMSM of Toyota Prius hybrid EV is chosen as the benchmark. Without loss of generality, all the proposed ferrite PMSM designs share the same stator, air-gap length, and stator/rotor pole combination as the commercial rare-earth one. As an initial analysis of a ferrite PMSM with the original structure of the benchmarking machine, it is found that the open-circuit air-gap flux density and the overall torque are significantly reduced. Hence, fluxfocusing technique with modified spoke type and multi-layer PM configurations are proposed to achieve approximately the 


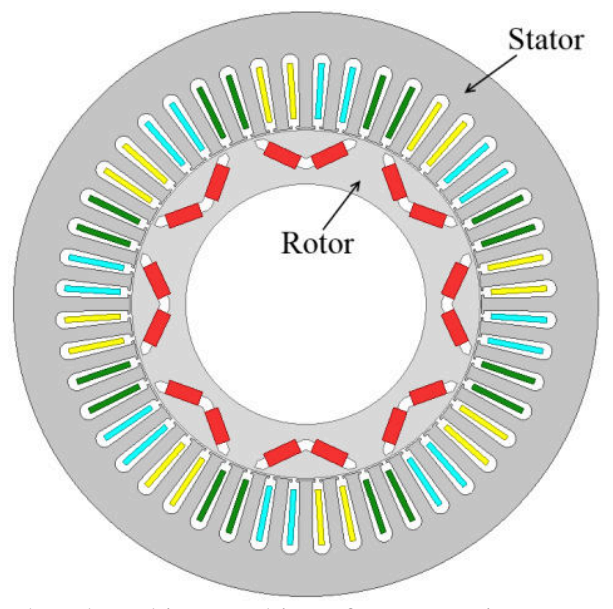

Fig. 1: The benchmarking machine of Toyota Prius

\begin{tabular}{|c|c|c|}
\hline Parameters & Value & Unit \\
\hline Stator Outer Diameter $\left(D_{s o}\right)$ & 269.24 & $\mathrm{~mm}$ \\
\hline Rotor Outer Diameter $\left(D_{r o}\right)$ & 160.4 & $\mathrm{~mm}$ \\
\hline Air gap Length $(g)$ & 0.75 & $\mathrm{~mm}$ \\
\hline Number of Poles $(p)$ & 8 & - \\
\hline Number of Slots $(q)$ & 48 & - \\
\hline Peak Torque $(T)$ & 300 & $\mathrm{~N} \cdot \mathrm{m}$ \\
\hline
\end{tabular}

Table 1: Key parameters of benchmarking machine.

same power and torque capabilities as the benchmarking machine. The influences of various geometric parameters on the machine characteristics are investigated and the performance of the optimal machines with different rotor configurations are evaluated and compared.

\section{Interior rare-earth PMSM by Toyota Prius}

The rare-earth IPMSM of Toyota Prius, depicted in Fig.1 and with its key machine parameter shown in Table.1, is chosen as the benchmarking motor. The machine is of three-phase type with two slots per pole per phase, which is facilitated by the short-pitched single-layer distributed windings, and has eight poles on the rotor and 48 slots on the stator. Based on the anti-periodic boundary condition, only one eighth of the machine suffices to form finite element analysis (FEA) model for computational efficiency. With the same structure, the open-circuit air-gap flux density in the ferrite PMSM can only reach one fourth of that of the rare-earth's as shown in Fig.2(a) due to the former's low magnetic energy. This also means that the PM torque in the ferrite machine is significantly reduced. Furthermore, the maximum output torque of both PMSMs are evaluated with the corresponding optimal current phase angles by FEA, and the results have showed that the ferrite machine could only deliver a maximum torque of two thirds that the rare-earth machine could, as illustrated in Fig.2(b). In order to provide a feasible design of ferrite PMSM for traction applications, flux squeezing configuration with high volume of ferrite magnet material is proposed in order to produce reasonable PM flux level in the air gap and hence the PM torque. Furthermore, rotor saliency should be exploited to harness extra reluctance torque, so that overall torque can be maximised.

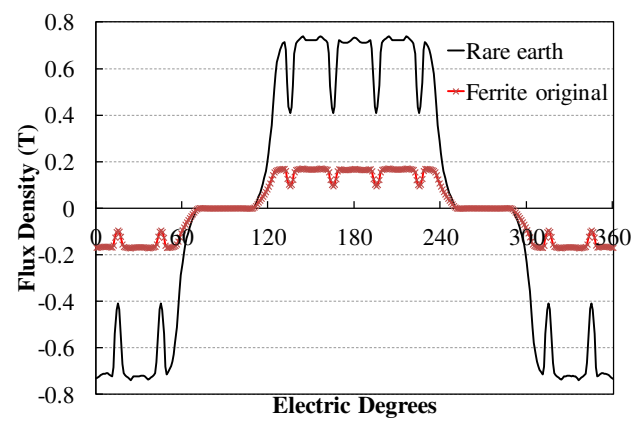

(a) Open-circuit air-gap flux density

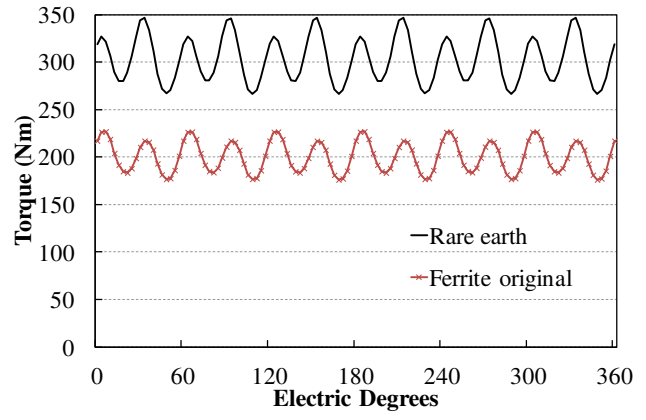

(b) maximum output torque

Fig. 2: Comparisons between rare earth and ferrite PMSM with original structure.

\section{IPMSM with multi-layer ferrite rotor}

The spoke type ferrite PM structure is proved to be effectively in focusing PM flux field and increasing the PM torque component. Based on the conventional spoke type (one-layer) configuration, multi-layer rotor structures are proposed to further improve the air-gap PM flux density distributions as well as rotor saliency. By considering the complexity and manufacturability of the rotor, the machines with up to three layers of ferrite PM, depicted in Fig.3, are investigated in this study. For easy comparisons between the proposed ferrite and the benchmarking machines, the same stator, air-gap length, and stator/rotor combination are assumed for all the machines. The rotor of each configuration is to be optimized accordingly to deliver maximum torque.

\subsection{One-layer spoke configuration}

In order to maximize the open-circuit flux density in the air gap, large volume of ferrite PM material is employed to carry out the flux concentration technique. Hence, the spoke type rotor configuration, as shown in Fig.3(a), is first investigated and optimized. With the maximum amount of ferrite PM that can be possibly allocated to the rotor, the PM air-gap flux density can be increased up to four times of the original design, and even exceed the benchmarking machine. The impacts of the shape and size of the PM layer on the torque generation are revealed by two-dimensional (2-D) FEA. The optimal current phase angle for each configuration, which can deliver the maximum torque, has been obtained through comprehensive search algorithm based on 2-D transient FEA. The output torque characteristics of the machines with different magnet lengths and widths are evaluated under the 


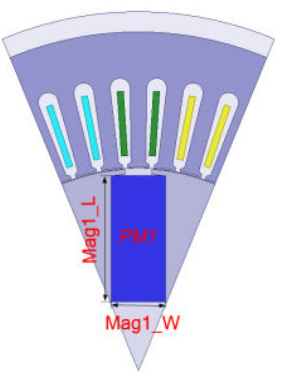

(a)one-layer

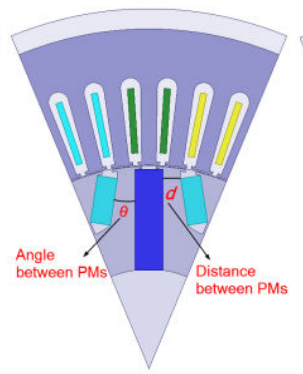

(b)two-layer

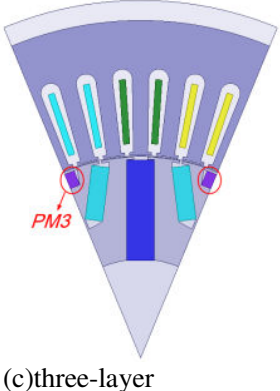

(c)three-layer
Fig. 3: Interior ferrite PMSM with multi-layer configurations.

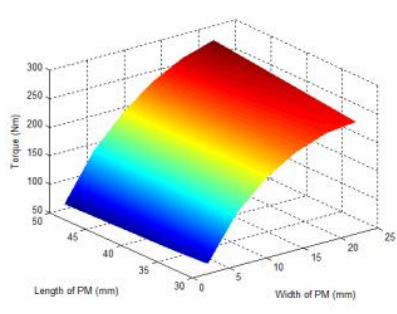

(a) maximum average torque

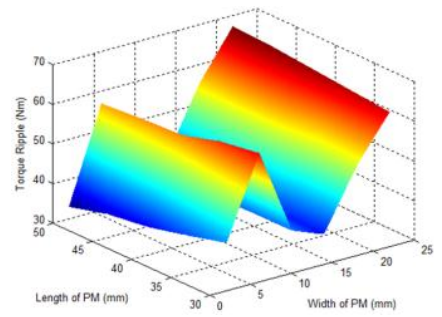

(b) P-P torque ripple
Fig. 4: Torque characteristics of the machine with one-layer ferrite maonet

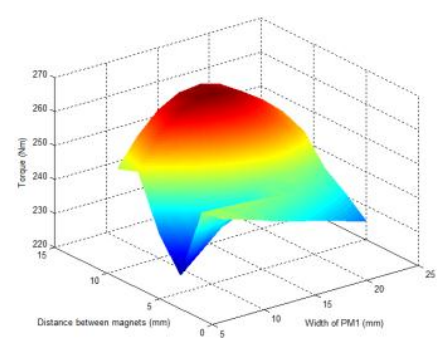

(a) $30 \mathrm{~mm}$

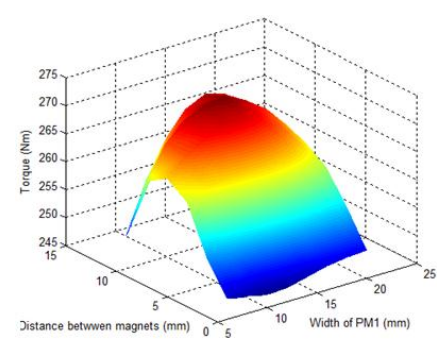

(c) $40 \mathrm{~mm}$

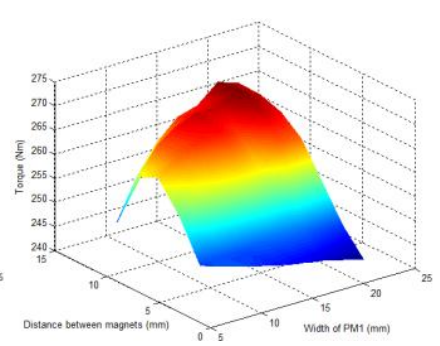

(b) $35 \mathrm{~mm}$

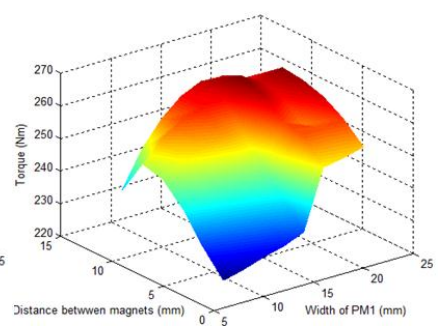

(d) $45 \mathrm{~mm}$
Fig. 5: Maximum average torque of machine with two-layer ferrite magnets and different length of first-layer magnet.

\begin{tabular}{|c|c|c|c|c|}
\hline Length of PMI $(\mathrm{mm})$ & 30 & 35 & 40 & 45 \\
\hline Maximum torque $(\mathrm{N} \cdot \mathrm{m})$ & 266.8 & 271.9 & 272.1 & 267.9 \\
\hline
\end{tabular}

Table 2: Torque at different lengths of first-layer magnet.

optimal current phase angles, and the average torque and peak-to-peak (P-P) torque ripple values are compiled and illustrated in Fig.4. It can be seen from Fig.4(a) that the average torque would increase as the length and width of the magnet get bigger. This means higher PM volume generally results in stronger magnetic field and larger torque output with this flux-focusing topology. On the other hand, only the width of ferrite PM imposes a major impact on the

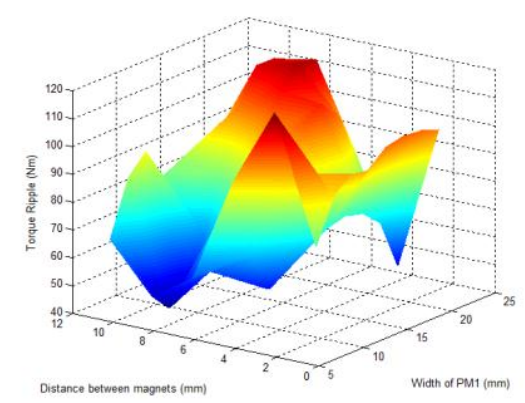

Fig. 6: P-P torque ripple of machine with two-layer ferrite magnets and first-layer magnet of $40 \mathrm{~mm}$ width.

corresponding torque ripple, and P-P torque ripple can be greatly suppressed with the PM width of $14 \mathrm{~mm}$. Overall, it can be inferred from Fig.4(a) that the machine with one-layer configuration could only deliver at most about $90 \%$ of the torque output of the benchmarking machine. The large volume of ferrite PM material, which accounts for the major mass of the rotor, would reduce the inductances and hence the rotor saliency. Consequently, the depreciated reluctance torque will lead to smaller overall torque despite higher PM air-gap flux density and hence larger PM torque being achieved in the machine. It is noteworthy that the flux weakening capability of the machine has also been compromised as a result of reduced inductances. Furthermore, the large PM in the one-layer configuration would result in much reduced space on the rotor for proper assembly such that basic robustness requirements could not be met in practice.

\subsection{Two-layer configuration}

In order to reduce the overall volume of ferrite PM material and improve the reluctance torque, two magnets are added to form a V-shape in each rotor pole, shown as a two-layer configuration in Fig.3(b). The sum of the widths of the three magnets in each pole is kept constant as $22 \mathrm{~mm}$ so that sufficient air-gap flux density could be sustained. In this case, two more parameters, namely distance and angle between the PM layers $d$ and $\theta$, should be optimized to deliver maximum torque. For the sake of simplicity, the PM layers in each pole are kept parallel $(\theta=0)$ to evaluate the impacts of the distance between PM layers as well as the length and width of first PM layer on the output torque. The corresponding maximum average torque values evaluated by 2 -D FEA are illustrated in Fig.5. It can be easily seen that the maximum average torque appears to be more sensitive to the distance between the PM layers $d$, and it reaches its maximum at $d=9 \mathrm{~mm}$ despite different lengths of first PM layer. As the air-gap flux density distributions are nearly same, it can be inferred that reluctance torque component reaches its maximum with layer distance of $9 \mathrm{~mm}$. It is noteworthy that larger size of the first PM layer does not guarantee higher output torque. The output torque reach its maximum as the length of first PM layer is $40 \mathrm{~mm}$ as listed in Table 2. As the total width of all three PMs in each pole is constant, the PM air-gap flux density stays almost the same. Consequently, the width of first PM layer has a minor 


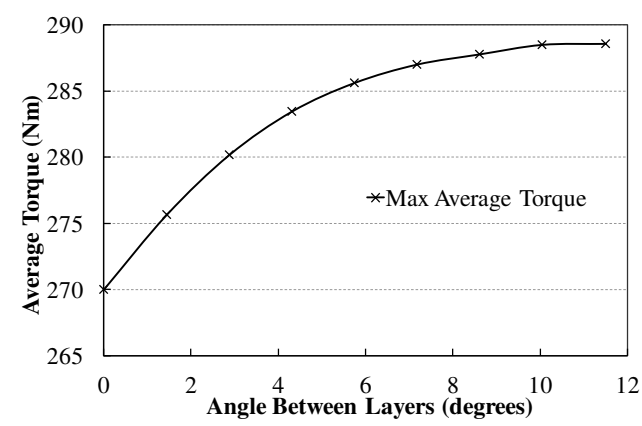

Fig. 7: Maximum average torque of the machine with different angle between the layers.

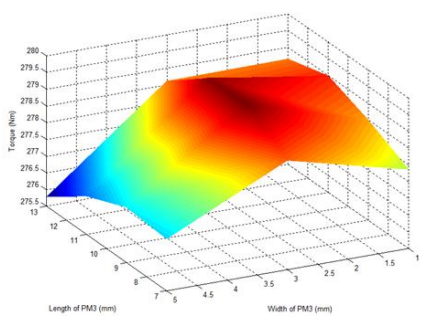

(a) maximum average torque

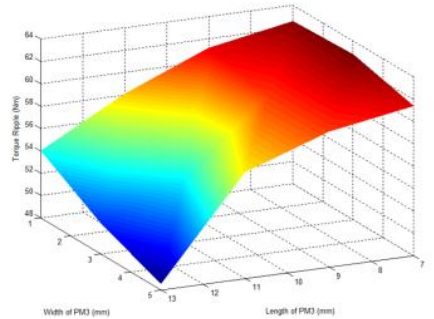

(b) P-P torque ripple
Fig. 8: Torque characteristics of the machine with three-layer ferrite magnets.

effect (less than 4\%) on the torque generation. Fig.5 reveals that maximum torque is delivered as the width of first PM layer is between $15 \mathrm{~mm}$ and $17 \mathrm{~mm}$, which will result in rather thin second PM layer between $2.5 \mathrm{~mm}$ and $3.5 \mathrm{~mm}$. As the ferrite PM has very low magnetic energy product, the second PM layer will be subjected to a high risk of demagnetization due to the strong armature reaction. The first PM layer width of $11 \mathrm{~mm}$ is considered as the optimal one with a maximum average output torque of $270.0 \mathrm{~N} \cdot \mathrm{m}$ and only half the torque ripple of $15 \mathrm{~mm}$ one, as shown in Fig.6.

Furthermore, the angle between the PM layers will influence the flux path and hence saturation of the rotor. It could be seen from Fig.3(b) that the total volume of ferrite PM will be reduced as the angle between the layers increases. However as $\theta$ gradually rises, the output torque will steadily improve and reach maximum at 10 degrees as shown in Fig.7. The improved reluctance torque component will compensate the loss of PM torque due to less ferrite PM material. Overall comparing with the one-layer machine, the reluctance torque in the two-layer one could be significantly improved. The optimal two-layer machine can achieve a total maximum torque of $288.6 \mathrm{~N} \cdot \mathrm{m}, 95.2 \%$ of the benchmarking machine.

\subsection{Three-layer configuration}

Another layer of ferrite PM is added in between the V-shape second layer for each pole to form a third-layer configuration, shown as Fig.3(c), so that the air-gap flux density distribution and rotor saliency of the machine could be improved. In order to simplify the analysis, the parameters of the first and second layers are kept the same as the optimal two-layer machine from the previous section. The influences of the length and width of the third magnet layer on the machine performance are shown by 2-D FEA. The machine with three-layer

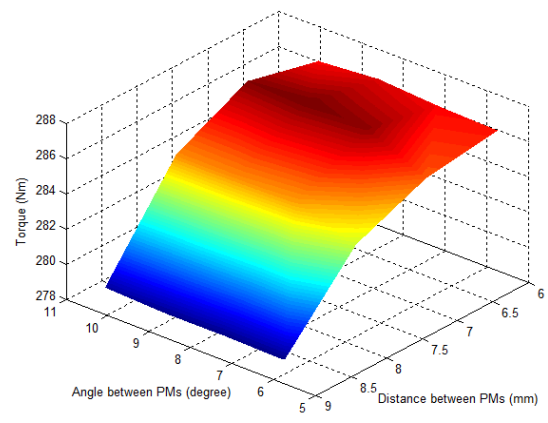

Fig. 9: Maximum average output torque of machine with three-layer ferrite magnets.

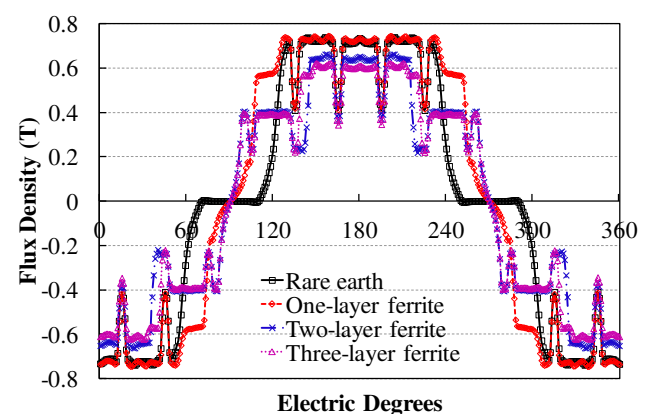

(a) Open-circuit air-gap flux density

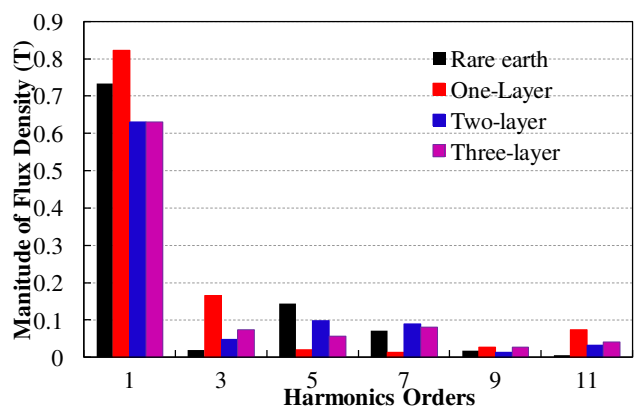

(b) Spectra

Fig. 10: Air-gap flux density comparisons among the optimal designs.

configuration has lower air-gap flux density than the corresponding two-layer one despite the higher ferrite material usage. The torque characteristics of the machine with different third-layer size are evaluated and depicted in Fig.8, which shows that the maximum torque of $279.6 \mathrm{~N} \cdot \mathrm{m}$ can be achieved when the third-layer PM is of length and width equalling $11 \mathrm{~mm}$ and $3 \mathrm{~mm}$ respectively. Although a proper size of third-layer PM improves rotor saliency and hence reluctance torque, the overall torque is still lower than the two-layer one. Moreover, it could be seen from Fig.8(b) that the larger the size of the third PM layer, the lower the torque pulsation.

Besides, the distance and angle between the first and second layers, which would also have direct influence on the air-gap flux density distribution, can be tuned to further improve the machine performance. The corresponding results are shown in Fig.9, which reveals that the torque can be further improved by increase in distance $d$ and particularly decrease in angle $\theta$. The optimal machine with three-layer configuration can deliver maximum average torque of $287.1 \mathrm{~N} \cdot \mathrm{m}$ with the distance $d$ of $7 \mathrm{~mm}$. Despite more complex rotor structure and 


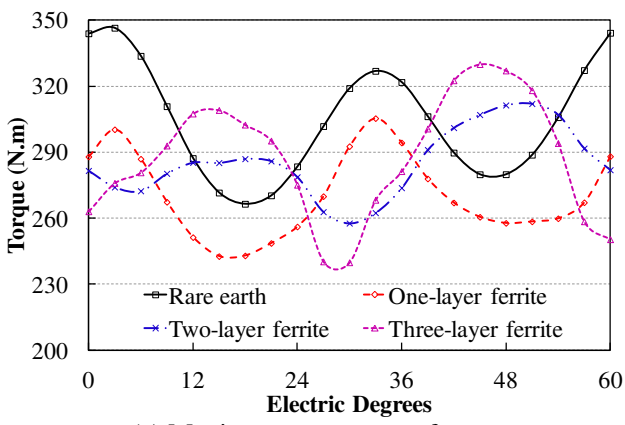

(a) Maximum torque waveforms

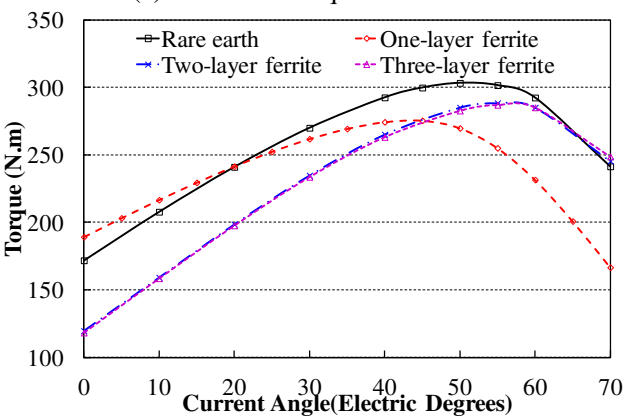

(b) Average torque with different current phase angle

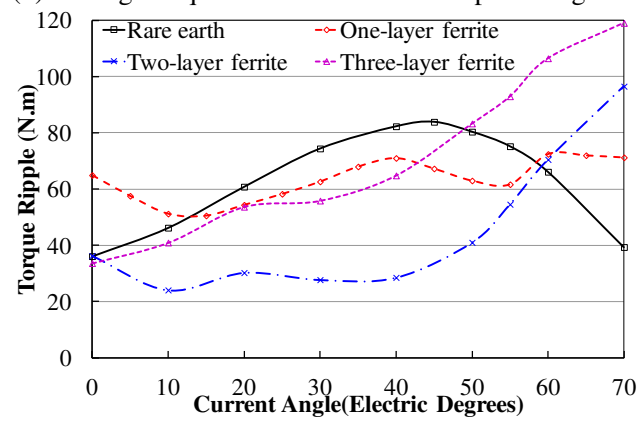

(c) P-P torque ripple with different current phase angle

Fig. 11: Torque comparisons among the optimal designs.

ferrite PM usage, the maximum output of the three-layer configuration is nearly the same as the two-layer one. The size of the third-layer PM is rather constrained by the secondlayer V-shape PMs, while additional flux bridges, which would lead to more severe saturations near the rotor surface, are required to retain the PM layer. Consequently, the thirdlayer configuration can hardly help to improve the torque density of the machine.

\section{Performance comparison}

The results so far suggest that the proposed novel multi-layer configuration can significantly increase the open-circuit airgap flux density and hence PM torque compared to the original one. Generally, more layers of PM will enhance rotor saliency and its associated reluctance torque. Nonetheless, different configurations have their own merits and drawbacks. Here, the optimal designs of different configurations obtained in the previous section are discussed and compared with the rare-earth benchmark. The open-circuit air-gap flux density distribution profiles of the machines and their spectra are derived and shown in Fig.10. The one-layer configuration produces the highest open-circuit air-gap fundamental flux density (12\% higher than the benchmark) due to its largest

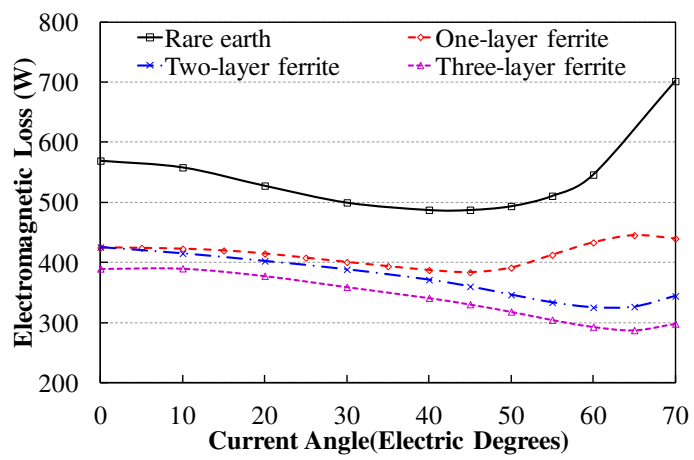

Fig. 12: Electromagnetic losses of the optimal designs.

\begin{tabular}{|c|c|c|c|c|}
\hline Parameter & $\begin{array}{c}\text { Rare } \\
\text { earth }\end{array}$ & $\begin{array}{c}\text { 1- } \\
\text { layer }\end{array}$ & $\begin{array}{c}\mathbf{2 -} \\
\text { layer }\end{array}$ & $\begin{array}{c}\text { 3- } \\
\text { layer }\end{array}$ \\
\hline Ferrite PM volume $\left(\mathrm{cm}^{3}\right)$ & - & 8.80 & 5.25 & 5.53 \\
\hline Fundamental flux density $(\mathrm{T})$ & 0.733 & 0.823 & 0.631 & 0.630 \\
\hline Max. torque $(\mathrm{N} \cdot \mathrm{m})$ & 303.2 & 275.4 & 288.6 & 287.1 \\
\hline Torque ripple $(\mathrm{N} \cdot \mathrm{m})$ & 80.4 & 67.3 & 54.6 & 92.9 \\
\hline Electromagnetic loss $(\mathrm{W})$ & 493.5 & 383.4 & 333.3 & 304.5 \\
\hline
\end{tabular}

Table 3: Performance comparison summary at peak output.

PM usage, while the two-layer and three-layer ones have a similar flux density level, which is about $14 \%$ less than the benchmark one. On the other hand, the situation is quite different for the torque characteristics, as shown in Fig.11. The one-layer ferrite PMSM delivers highest torque with current phase angle below 20degrees due to its largest fundamental PM flux density, while the two-layer and threelayer ones produce highest torque with current phase angle above 70degrees owing to their high rotor saliency. However, the rare-earth benchmark machine has the highest maximum output torque, while the one-layer ferrite one has the lowest one. Moreover, the two-layer and three-layer designs have very close output torque values, but the P-P torque ripple of the two-layer one is the smallest over most of the operational range. However, the torque ripple of the ferrite PMSM with multi-layer configuration increases dramatically with current phase angle above 50degrees.

As the ferrite magnet material is usually nonconductive, PM eddy current loss is almost eliminated. The electromagnetic losses of the machines at rated current excitations are evaluated by 2-D FEA and compared in Fig.12. The same stator would result in same winding resistive losses for easy comparison. The FEA results show that all the machines have very similar iron core loss characteristics owing to the similar level of flux density distributions. The rare-earth benchmark machine has the highest overall losses due to the existence of PM eddy current loss. Moreover, the core loss gradually declines as the PM layer number rises in the ferrite PMSM. The general summary of the machines with different configurations, such as ferrite magnet volume, air-gap flux density, maximum average torque, $\mathrm{P}-\mathrm{P}$ torque ripple, and electromagnetic loss, are compared in Table 3. As the layer number increases, the complexity of the rotor would impose a practical burden on the manufacture. By taking all the factors into consideration, the ferrite PMSM with two-layer configuration is selected as the best design for traction applications. Although the maximum torque output is still $4 \%$ 
less than the rare-earth benchmark one, the electromagnetic loss is reduced by $32.5 \%$.

\section{Conclusion}

A novel multi-layer interior ferrite PMSM is proposed in this study to provide an alternative solution to replace commercial rare-earth one for high performance traction applications. The performance and torque characteristics of the ferrite PMSM with up to three magnet layers are comprehensively studied. The one-layer configuration can achieve even higher opencircuit flux density than the rare-earth benchmark by flux focusing with excessive ferrite PM usage. However, the maximum torque of the machine is rather small due to its low rotor saliency and hence reduced reluctance torque. As PM layer number rises, the rotor saliency and hence reluctance torque improves considerably so that high overall output torque could be achieved despite of reduced PM torque. Moreover, the two-layer and three-layer configurations have almost the same average torque with the two-layer having lower torque pulsations. The optimal two-layer interior ferrite PMSM could deliver nearly $95.2 \%$ maximum torque of the rare-earth benchmark machine with over $30 \%$ drop in electromagnetic loss. The results underpin the 2-layer interior ferrite PMSM is a viable alternative for traction applications.

\section{Acknowledgements}

This work is supported by the Engineering and Physics Science Research Council, U.K., Ref. EP/I038543/1.

\section{References}

[1] C.C.Chan,"An overview of electric vehicle technology," Proc. IEEE, vol. 81, no. 9, pp. 1202-1213, Sep. 1993.

[2] Z. Q. Zhu and D. Howe, "Electrical machines and drives for electric, hybrid, and fuel cell vehicles," Proc. IEEE, vol. 95, no. 4, pp.746-765, Apr. 2007.

[3] A. Wang, Y. Jia, and W. L. Soong, "Comparison of five topologies for an interior permanent-magnet machine for a hybrid electric vehicle," IEEE Trans. Magn., vol. 47, no. 10, pp. 3606-3609, Oct. 2011.

[4] K. T. Chau, C. C. Chan, and C. Liu, "Overview of permanent-magnet brushless drives for electric and hybrid electric vehicle," IEEE Trans. Ind. Electron., vol. 55, no. 6, pp. 2246-2257, Jun. 2008.

[5] S. Javadi and M. Mirsalim, "Design and analysis of $42 \mathrm{~V}$ coreless axial-flux permanent-magnet generators for automotive applications," IEEE Trans. Magn., vol. 46, no. 4, pp. 1015-1023, Apr. 2010.

[6] E. Sulaiman, T. Kosaka, and N. Matsui, "High power density design of 6-slot-9pole hybrid excitation flux switching machine for hybrid electric vehicles," IEEE Trans. Magn., vol. 47, no. 10, pp. 4453-4456, Oct. 2011.

[7] W. Fei, P. C. K. Luk, et al, "A novel permanent-magnet flux switching machine with an outer-rotor configuration for in-wheel light traction applications," IEEE Trans. Ind. Appl., vol. 48, no. 5, pp. 1496-1506, Sep./Oct. 2012.
[8] N. Hashemnia and B. Asaei, "Comparative study of using different electric motors in the electric vehicles," in Proc. Int. Conf. Electr. Mach., 2008, pp. 1-5.

[9] S. Hlioui, L. Vido, Y. Amara, M. Gabsi, A. Miraoui, and M. Lecrivain, "Design of a synchronous machine with concentric stator windings and permanent magnets in focusing configuration," in Porc. Int. Aegean Conf. Electr. Mach. and Power Electron., 2007, pp. 507-512.

[10] K. Sone, M. Takemoto, S. Ogasawara, K. Takezaki, and H. Akiyama, "A ferrite PM in-wheel motor without rareearth materials for electric city commuters," IEEE Trans. Magn., vol. 48, no. 11 pp. 2961-2964, Nov. 2012.

[11] A. Vagati, et al, "Ferrite assisted synchronous reluctance machines: A general approach," in Proc. Int. Conf. Electr. Mach., 2012, pp. 1315-1321.

[12] E. E. Montalvo-Ortiz, S. N. Foster, J. G. Cintron-Rivera, and E. G. Strangas, "Comparison between a spoke-type PMSM and a PMASynRM using ferrite magnets," in Proc. Int. Conf. Electr. Mach. and Drives, 2013, pp. 1080-1087.

[13] M. Barcaro, N. Bianchi, "Interior PM machines using ferrite to substitute rare-earth surface PM machines," in Proc. Int. Conf. Electr. Mach., 2012, pp. 1339-1345.

[14] E. Armaando, et al "Performance of IPM-PMASR motors with ferrite injection for home appliance washing machine," in Proc. IEEE Ind. Appl. Soc. Annu. Meeting, 2008, pp.1-6.

[15] B. Lee, G.-H. Kang, J. Hur, and D.-W. You, "Design of spoke type BLDC motors with high power density for traction applications," in Proc. IEEE Ind. Appl. Soc. Annu. Meeting, 2004, pp.1068-1074.

[16] D. G. Dorrell, M.-F. Hsieh, and A. M. Knight, "Alternative rotor designs for high performance brushless permanent magnet machines for hybrid electric vehicle," IEEE Trans. Magn., vol. 48, no. 2, pp. 835-838, Feb. 2012.

[17] K.-C. Kim and J. Lee, "The dynamic analysis of a spoke type permanent magnet generator with large overhang." IEEE Trans. Magn., vol. 41, no. 10, pp.3805-3807, Oct. 2005.

[18] M. M. Rahman, K.-T. Kim, and J. Hur, "Design and analysis of neodymium free spoke-type motor with segmented wing shape permanent magnet for concentrating flux density," in Proc. IEEE Energy Convers. Congr. Expo., 2013, pp. 4991-4997.

[19] M. R. Mohammad, K.-T. Kim, and J. Hur, "Design and analysis of a spoke type motor with segmented pushing permanent magnet for concentrating air-gap flux density," IEEE Trans. Magn., vol. 49, no. 5, pp. $2397-$ 2400, May 2013.

[20] H.-W. Kim, et al, "Design of new spoke type brushless DC motor for neodymium permanent magnet free," in Proc. IEEE Vehicle Power and Propulsion Conf. 2012, pp. 133-137.

[21] S.-I. Kim, et al "Characteristics comparison of a conventional and modified spoke-type ferrite magnet motor for traction drives of low-speed electric vehicles," IEEE Trans. Ind. Appl., vol. 49, no. 6, pp. 2516-2523, Nov./Dec. 2013. 